\title{
Cardiopulmonary Exercise Testing in Pediatrics
}

Citation for published version (APA):

Takken, T., Bongers, B. C., Van Brussel, M., Haapala, E. A., \& Hulzebos, E. H. J. (2017).

Cardiopulmonary Exercise Testing in Pediatrics. Annals of the American Thoracic Society, 14(supp. 1), S123-S128. https://doi.org/10.1513/AnnalsATS.201611-912FR

Document status and date:

Published: 01/07/2017

DOI:

10.1513/AnnalsATS.201611-912FR

Document Version:

Publisher's PDF, also known as Version of record

Document license:

Taverne

\section{Please check the document version of this publication:}

- A submitted manuscript is the version of the article upon submission and before peer-review. There can be important differences between the submitted version and the official published version of record.

People interested in the research are advised to contact the author for the final version of the publication, or visit the DOI to the publisher's website.

- The final author version and the galley proof are versions of the publication after peer review.

- The final published version features the final layout of the paper including the volume, issue and page numbers.

Link to publication

\footnotetext{
General rights rights.

- You may freely distribute the URL identifying the publication in the public portal. please follow below link for the End User Agreement:

www.umlib.nl/taverne-license

Take down policy

If you believe that this document breaches copyright please contact us at:

repository@maastrichtuniversity.nl

providing details and we will investigate your claim.
}

Copyright and moral rights for the publications made accessible in the public portal are retained by the authors and/or other copyright owners and it is a condition of accessing publications that users recognise and abide by the legal requirements associated with these

- Users may download and print one copy of any publication from the public portal for the purpose of private study or research.

- You may not further distribute the material or use it for any profit-making activity or commercial gain

If the publication is distributed under the terms of Article $25 \mathrm{fa}$ of the Dutch Copyright Act, indicated by the "Taverne" license above, 


\title{
Cardiopulmonary Exercise Testing in Pediatrics
}

\author{
Tim Takken ${ }^{1}$, Bart C. Bongers ${ }^{2}$, Marco van Brussel ${ }^{1}$, Eero A. Haapala ${ }^{3,4}$, and Erik H. J. Hulzebos ${ }^{1}$ \\ ${ }^{1}$ Child Development and Exercise Center, Wilhelmina Children's Hospital, University Medical Center Utrecht, Utrecht, the \\ Netherlands; ${ }^{2}$ Department of Epidemiology, Care and Public Health Research Institute, Maastricht University, Maastricht, the Netherlands; ${ }^{3}$ Sport \\ and Exercise Medicine, Faculty of Sport and Health Sciences, University of Jyväskylä, Jyväskylä, Finland; and ${ }^{4}$ Department of Physiology, \\ Institute of Biomedicine, School of Medicine, University of Eastern Finland, Kuopio Campus, Finland
}

\begin{abstract}
Aerobic fitness is an important determinant of overall health. Higher aerobic fitness has been associated with many health benefits. Because myocardial ischemia is rare in children, indications for exercise testing differ in children compared with adults. Pediatric exercise testing is imperative to unravel the physiological mechanisms of reduced aerobic fitness and to evaluate intervention effects in children and adolescents with a chronic disease or disability. Cardiopulmonary exercise testing includes the
\end{abstract}

measurement of respiratory gas exchange and is the gold standard for determining aerobic fitness, as well as for examining the integrated physiological responses to exercise in pediatric medicine. As the physiological responses to exercise change during growth and development, appropriate pediatric reference values are essential for an adequate interpretation of the cardiopulmonary exercise test.

Keywords: physical fitness; aerobic capacity; exercise testing; exercise physiology; children

(Received in original form November 21, 2016; accepted in final form April 7, 2017)

Correspondence and requests for reprints should be addressed to Tim Takken, M.Sc., Ph.D., Child Development \& Exercise Center, Wilhelmina Children's Hospital, University Medical Center Utrecht, Room KB.02.056.0, P.O. Box 85500, NL-3508 GA Utrecht, the Netherlands. E-mail: t.takken@umcutrecht.nl

Ann Am Thorac Soc Vol 14, Supplement 1, pp S123-S128, Jul 2017

Copyright (C) 2017 by the American Thoracic Society

DOI: 10.1513/AnnalsATS.201611-912FR

Internet address: www.atsjournals.org

Remarkable physiological, anatomical, and psychological transformations due to growth, maturation, and development affecting physical fitness, occur during childhood and adolescence. Physical fitness is a principal concept in (clinical) exercise physiology, and can be considered as an integrated measure of most, if not all, body functions involved in the performance of daily physical activity and physical exercise (1). These body functions include aerobic fitness, body composition, muscular strength, power, speed, balance, flexibility, and hand-eye coordination (2). A high level of physical fitness in childhood and adolescence has been linked to reduced risk for obesity and cardiovascular diseases, and improved musculoskeletal health and mental health $(1,3)$. Pediatric exercise testing is a valuable, noninvasive procedure to evaluate physical fitness throughout childhood and adolescence.
Aerobic fitness is one of the most important components of physical fitness. A higher aerobic fitness has been related to a lower morbidity and mortality in healthy adults $(4,5)$ and in adults with cardiovascular and pulmonary diseases (6). In children and adolescents, aerobic fitness also has been reported to be an important marker of health. For example, aerobic fitness has been found to be inversely associated with total adiposity (7) and cardiovascular risk factors (8). Moreover, in children and young adults with congenital heart or lung disease, a low aerobic fitness predicts morbidity and mortality in later years (9-12).

The measurement of maximal $\dot{\mathrm{V}}_{2}$ $\left(\dot{\mathrm{V}}_{\mathrm{O}_{2 \max }}\right)$ or peak $\dot{\mathrm{V}}_{\mathrm{O}_{2}}\left(\dot{\mathrm{V}}_{\mathrm{O}_{2 \text { peak }}}\right)$ during a progressive cardiopulmonary exercise test up to maximal exertion is widely considered the gold standard for assessing aerobic fitness $(13,14)$. The noninvasive and dynamic nature of the performed measurements during cardiopulmonary exercise testing provides important information that can be used for (differential) diagnostic, prognostic, and evaluative purposes in medicine. As opposed to healthy children, children with a chronic condition are often restricted in their participation in physical activities and sport programs as a consequence of real or perceived limitations imposed by their condition. The chronic condition itself often causes hypoactivity, which leads to a deconditioning effect, a reduction in functional ability, and a downward spiral of further hypoactivity (15). Hypoactive children are often at greater risk of preventable health problems, such as obesity and cardiometabolic diseases. Many children with a chronic condition have reduced levels of aerobic fitness, as can be seen in Figure 1. This figure depicts $\dot{\mathrm{V}}_{\text {2peak }} z$-scores in different chronic conditions collected in studies performed by our research group. The reduced 


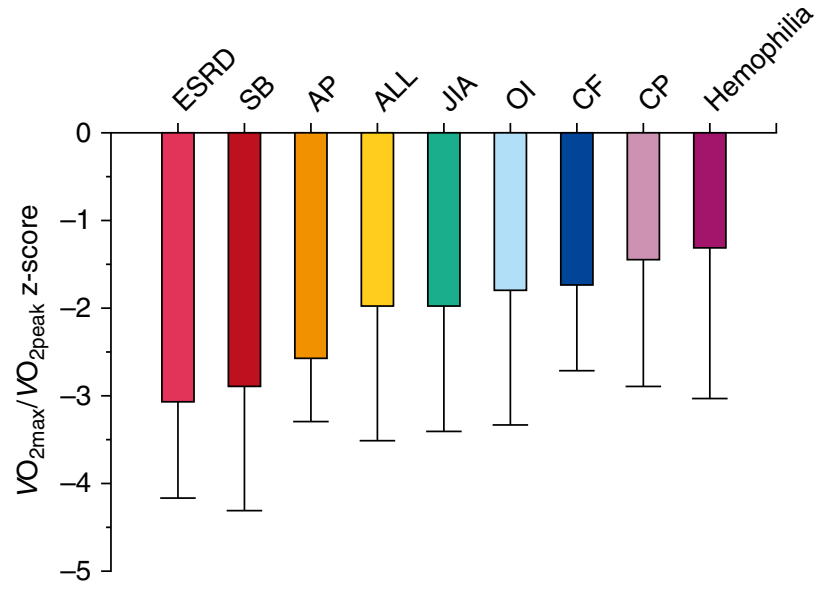

Figure 1. Aerobic fitness $\left(\dot{\mathrm{V}}_{2 \text { peak }}\right)$ of children with a chronic condition. Data is presented as mean $\pm S D$. $A L L=$ acute lymphoblastic leukemia; $A P=$ achondroplasia; $C F=$ cystic fibrosis, $\mathrm{CP}=$ cerebral palsy; $\mathrm{ESRD}=$ end-stage renal disease; $\mathrm{JIA}=$ juvenile idiopathic arthritis; $\mathrm{OI}=$ osteogenesis imperfecta; $\mathrm{SB}=$ spina bifida; $\dot{\mathrm{V}}_{2 \text { max }}$, maximal $\dot{\mathrm{V}}_{2} ; \dot{\mathrm{V}}_{\mathrm{O}_{2} \text { peak }}=$ highest measured $\dot{\mathrm{V}}_{2}$. Note: data are extracted from studies of our research group (16-23).

levels of aerobic fitness are generally caused by a combination of disease-related pathophysiology, treatment (e.g., medication), hypoactivity, and deconditioning.

Next, in regard to adjusting and optimizing treatment and disease management, results from pediatric exercise testing are increasingly used to compose individually tailored exercise training programs. A physical exercise training program might be indicated when aerobic fitness is significantly reduced compared with sex- and age-matched normative values (i.e., lower than -2 SD). Through individualized physical exercise training, the capacity of the pulmonary, cardiovascular, hematopoietic, neuromuscular, musculoskeletal, and metabolic systems, and thereby aerobic fitness, increases considerably.

\section{Pediatric Exercise Physiology}

During physical exercise, adequate interactions are required between different physiological systems to transport an adequate amount of oxygen and nutrients to the exercising muscles, and to remove metabolically produced products, such as carbon dioxide, from the exercising muscles. These responses of the individual physiological systems are linked to cell respiration with the aim to maintain homeostasis, with adequate responses to exercise-induced allostatic load (allostasis). The cardiopulmonary system is continuously stressed during progressive physical exercise to facilitate an increase in oxygen transport. Oxygen transport enlarges due to increases in cardiac output (heart rate $\times$ left ventricular stroke volume), $\dot{\mathrm{V}}_{\mathrm{E}}$ (breathing frequency $X$ $\mathrm{VT}$ ), and the arteriovenous oxygen difference, when the exercising muscles require more oxygen to sustain muscular contractions.

Aerobic fitness, aerobic capacity, aerobic power, maximal aerobic power, aerobic work capacity, cardiopulmonary fitness, cardiorespiratory fitness, cardiovascular fitness, and $\mathrm{VO}_{2 \max }$ all refer to the same concept, and can be defined as the maximal capacity of the pulmonary and cardiovascular system to take up and transport oxygen to the exercising muscles, and of the exercising muscles to extract and use oxygen from the blood for aerobic energy production during progressive exercise with large muscle groups up to maximal exertion. According to the Fick equation (24), $\dot{\mathrm{V}}_{\mathrm{O}_{2 \max }}$ is the product of the maximal cardiac output and the maximal arteriovenous oxygen difference. Each of the systems involved in the pathway for oxygen from the atmosphere to the mitochondria might be a physiological limiting factor for

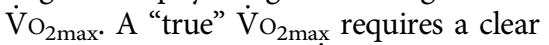
plateau (asymptote) in $\dot{\mathrm{V}}_{2}$ despite an increasing work rate (exercise intensity). Because this plateau is infrequently observed in adults (25), as well as in children and adolescents $(26,27)$, the highest measured $\dot{\mathrm{V}}_{2}\left(\dot{\mathrm{V}}_{\mathrm{O}_{2 \text { peak }}}\right)$ is often used interchangeably with $\dot{\mathrm{V}}_{2 \max }$ to define aerobic fitness.
During the initial phase of progressive physical exercise, increased cardiac output is primarily regulated by an increased left ventricular stroke volume in response to an increase in the volume of blood filling the heart (the end-diastolic volume), when all other factors remain constant (FrankStarling mechanism). It is assumed that, when exercise intensity increases (as of about $50 \%$ of $\dot{\mathrm{V}}_{2 \max }$ ), cardiac output will increase, mainly by further increases in heart rate. It is of great importance to realize that maximal heart rate is genetically predetermined, as well as that the maximal heart rate achieved by children and adolescents is independent of age (28). Although maximal heart rate decreases with age in adults (29), the maximal heart rate remains relatively stable, around 195 (bicycle) to 200 beats per min (treadmill) in children and adolescents (30). Furthermore, the maximal left ventricular stroke volume during progressive physical exercise differs significantly between children and adults. Compared with adults, children obtain a smaller left ventricular stroke volume during exercise, which they compensate for by a higher heart rate during exercise. The smaller left ventricular stroke volume in children and adolescents is an important limiting factor of their oxygen transport system.

The increased $\dot{V}$ e during the early stages of progressive physical exercise can be almost completely explained by increases in VT. When the VT equals approximately $50 \%$ of the VC of the lungs, VE increases merely by increases in breathing frequency. There are specific developmental aspects noticeable during childhood and adolescence, such as an increase in $\dot{V}_{E}$ and the efficiency of ventilation with age (30). The latter can be explained by a decreasing breathing frequency, coinciding with an increasing VT and depth of breathing (30).

During progressive physical exercise up to maximal exertion, ventilation is seldom an exercise-limiting factor. Children with significant lung disease can develop a pulmonary limitation to exercise, which can contribute to exercise intolerance and dyspnea. In these children, ventilation may be insufficient for the metabolic demand, as demonstrated by an inadequate breathing reserve (BR): $\left.\mathrm{BR}=\left(\mathrm{MVV}-\dot{\mathrm{V}} \mathrm{E}_{\text {peak }}\right) /(\mathrm{MVV} \times 100)\right]$, where MVV is maximal voluntary ventilation and $\dot{\mathrm{V}}_{\text {peak }}$ is $\dot{\mathrm{V}}_{\mathrm{E}}$ at peak exercise. BR is normally higher than $15 \%$ at peak exercise; a BR below $15 \%$ might be indicative of expiratory flow limitation, 
dynamic hyperinflation, and/or the retention of arterial carbon dioxide. In children, MVV can be estimated by multiplying $\mathrm{FEV}_{1}$ by 35 (31). It is possible that a ventilatory limitation restricting maximal exercise capacity only exists in children and adolescents with a moderately-to-severely reduced lung function (predicted $\mathrm{FEV}_{1}$ below 65\%) (15). These children might also develop gas exchange impairments with exercise, as demonstrated by decreased peripherally measured oxygen saturation and or an increased partial endtidal carbon dioxide tension.

The arteriovenous oxygen difference and the oxygen transport capacity of the blood are also of importance during physical exercise. The arteriovenous oxygen difference refers to the difference in oxygen concentration between the arterial blood and the venous blood. This represents the amount of oxygen that is extracted from the blood and used by the exercising muscles and organ systems. During maximal exercise, there is no difference in arteriovenous oxygen difference between prepubertal boys and girls $(32,33)$. However, postpubertal boys have higher arteriovenous oxygen difference than that of postpubertal girls. Adult men and women have a considerably greater maximal arteriovenous oxygen difference compared with boys and girls (34). In adults, men demonstrate higher arteriovenous oxygen difference than women. During submaximal exercise, the arteriovenous oxygen difference is somewhat higher in children compared with adults $(15,34)$. This phenomenon can be explained by the fact that children compensate for their lower cardiac output by extracting relatively more oxygen from the blood. The oxygen transport capacity of the blood increases slowly during childhood, resulting in significant sex differences in adulthood. On average, adult men have a higher hemoglobin concentration in their blood compared with adult women (35). The most commonly observed cardiovascular, pulmonary, and metabolic adult-child differences are depicted in Table 1.

\section{Pediatric Exercise Testing in Clinical Practice}

The determination of oxygen and carbon dioxide concentrations in expired air at regular intervals throughout a cardiopulmonary exercise test up to maximal exertion is the gold standard for

Table 1. Commonly observed differences in exercise physiological parameters between adults and children

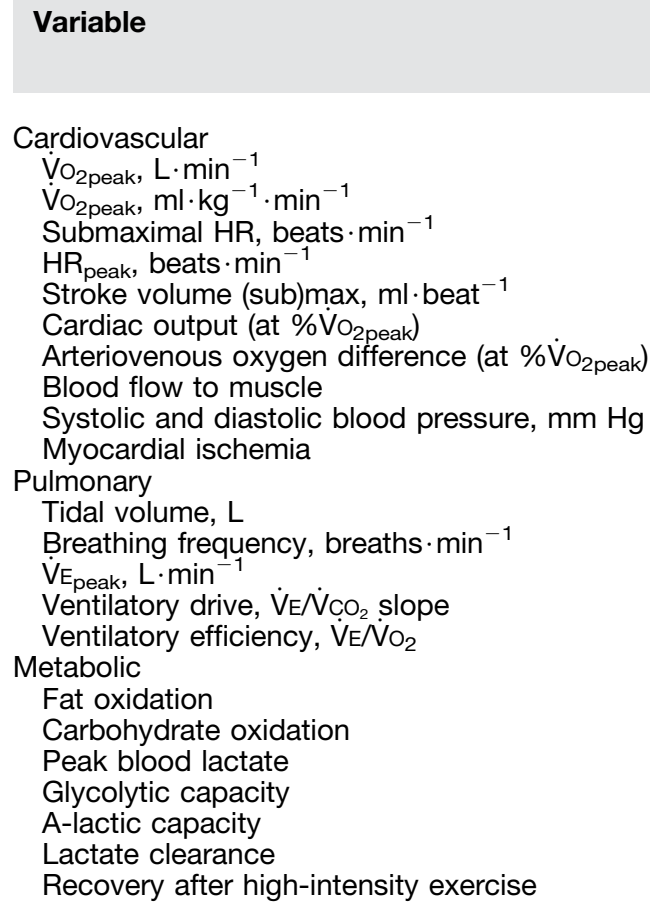

Lower

Higher

Higher

Higher

Lower

Lower

Higher

Higher

Lower

Rare

Lower

Higher

Lower

Higher

Lower

Higher

Lower

Lower

Lower

Lower

Same

Faster

Definition of abbreviations: $\mathrm{HR}=$ heart rate; $\mathrm{HR}_{\text {peak }}=$ peak heart rate; $\dot{\mathrm{V}}_{\mathrm{E}_{\text {peak }}}=$ peak $\dot{\mathrm{V}}_{\mathrm{E}} ; \dot{\mathrm{V}}_{\mathrm{O}_{2 \text { peak }}}=$ peak $\dot{\mathrm{V}} \mathrm{O}_{2}$.

the determination of $\dot{\mathrm{V}}_{2 \max }$ or $\dot{\mathrm{V}}_{2 \text { peak }}$. In addition, the integrated response of different physiological systems (the cardiovascular, pulmonary, hematopoietic, neuromuscular, musculoskeletal, and metabolic systems) can be objectively evaluated at rest, during progressive exercise up to maximal exertion, and during recovery. This integrative approach and analysis of the different physiological systems are of additional value compared with the evaluation of each physiological system separately at rest. The noninvasive and dynamic nature of the performed measurements provides the clinician important information that can be used for diagnostic, prognostic, and evaluative purposes (30). Exercise testing can be used to identify physiological causes for exerciserelated complaints and symptoms, as well as to assess (functional) exercise capacity and exercise-limiting factors, including pathophysiological changes. Therefore, cardiopulmonary exercise testing can support physiological reasoning and clinical decision-making. Next, as to its well recognized value in cardiology, pulmonology, and sports medicine, many other medical specialties (e.g., metabolic disorders, oncology) are currently showing their interest in the data and interpretation of cardiopulmonary exercise testing, often omitting more comprehensive assessments.

$\dot{\mathrm{V}}_{\mathrm{O}_{2 \text { max }}}$, or $\dot{\mathrm{V}}_{\mathrm{O}_{2 \text { peak }}}$, is one of the best known and most frequently determined cardiopulmonary exercise test parameter. For clinicians and researchers, normative values for $\dot{\mathrm{V}}_{\text {2peak }}$ facilitate adequate interpretation of aerobic fitness. Pediatric normative values for $\dot{\mathrm{V}}_{\text {2peak }}$ normalized for body mass are depicted in Figure 2. However, in addition to $\dot{\mathrm{V}}_{2 \text { peak }}$, several other parameters should be determined to help enable an adequate and complete interpretation of the cardiopulmonary exercise test. These parameters, their derivatives, and perceptual responses of the child are a direct or indirect reflection of the previously mentioned integrated physiological interactions during physical exercise. A selection of relevant exercise parameters is summarized in Figure 3.

There are different methodologies to perform a cardiopulmonary exercise test, and many exercise laboratories use their own standardized protocols. When a child's 

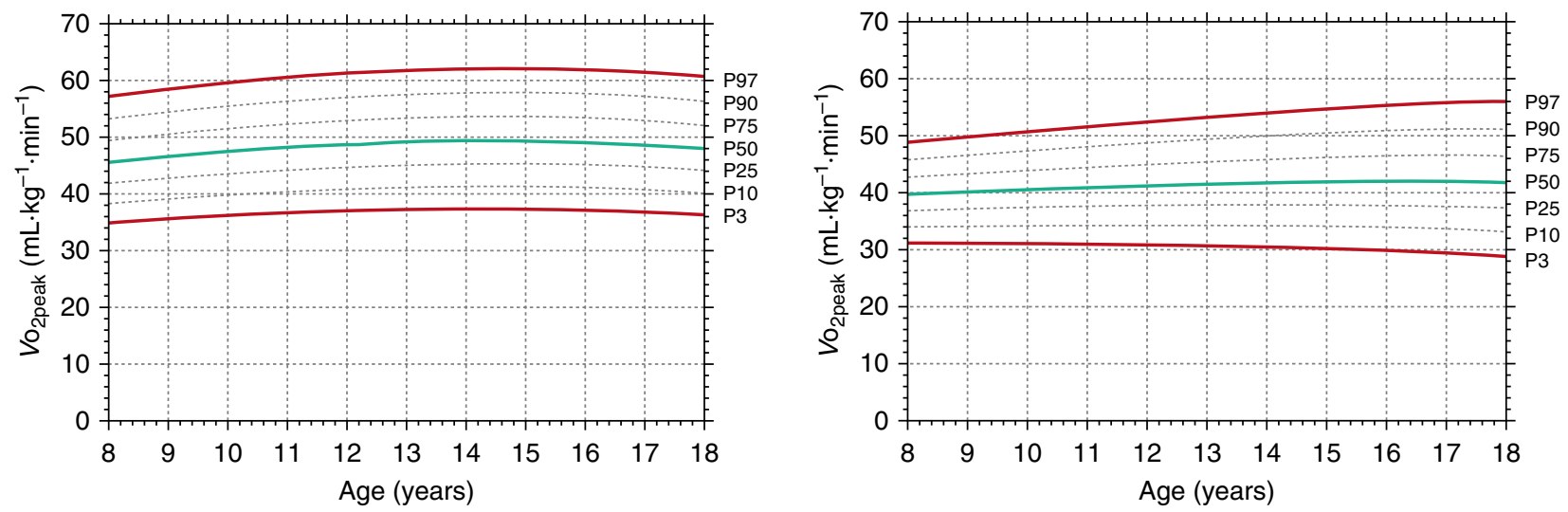

Figure 2. Age-related centile charts for aerobic fitness $\left(\dot{\mathrm{V}}_{2 \text { peak }} / \mathrm{kg}\right)$ for boys (left graph) and girls (right graph). Green curves show medians and red curves show the upper and lower limits of normal. $\mathrm{P}=$ percentile; $\dot{\mathrm{V}}_{2 \text { peak }}=$ highest measured $\dot{\mathrm{V}}_{2}$ per kilogram body mass. Note: adapted from Reference 30 .

performance is compared with reference values, it is necessary to standardize the cardiopulmonary exercise test according to the testing procedures and methodology that were used to establish the reference values (30). In addition, the choice for an appropriate exercise protocol is dependent on the complaints and symptoms, as well as on the physical fitness level, of the child. The Bruce protocol is the most frequently used treadmill protocol for cardiopulmonary exercise testing in children and adolescents (37). However, important physiological measurements during exercise, including the electrocardiogram and blood pressure, are easier to assess and of better quality using a cycle ergometer. Moreover, maximal work rate can be assessed accurately using a cycle ergometer, which is not feasible when using a treadmill. In young children, the speed of the treadmill protocol is often a restrictive

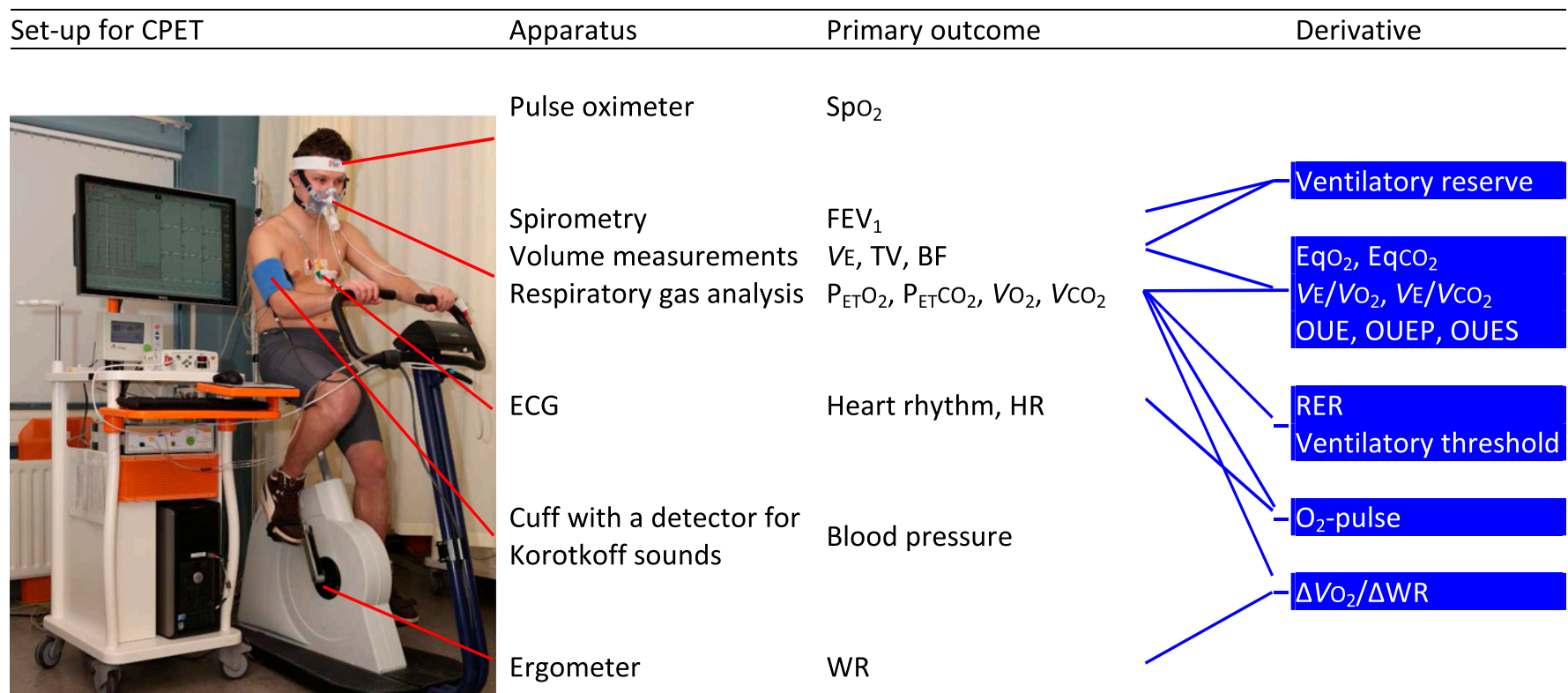

Borg-scale or VAS

Dyspnea, leg fatigue

Figure 3. Selection of important parameters measured during cardiopulmonary exercise testing in pediatric populations. BF $=$ breathing frequency (breaths $\left.\cdot \mathrm{min}^{-1}\right)$; CPET = cardiopulmonary exercise testing; $\Delta \mathrm{V}_{2} / \Delta \mathrm{WR}=$ oxygen cost of work $\left(\mathrm{ml} \cdot \mathrm{min}^{-1} \cdot \mathrm{W}^{-1}\right.$ ); EqCO $\mathrm{CO}_{2}=$ ventilatory equivalent for carbon dioxide; $\mathrm{EqO}_{2}=$ ventilatory equivalent for oxygen; $\mathrm{HR}=$ heart rate (beats $\cdot \mathrm{min}^{-1}$ ); OUE $=\dot{\mathrm{V}}_{2}$ efficiency; OUEP $=\dot{\mathrm{V}}_{2}$ efficiency plateau; OUES $=\dot{\mathrm{V}} \mathrm{O}_{2}$ efficiency slope; $\mathrm{PET}_{\mathrm{CO}_{2}}=$ partial end-tidal carbon dioxide tension $(\mathrm{mm} \mathrm{Hg}) ; \mathrm{PET}_{\mathrm{O}_{2}}=$ partial end-tidal oxygen tension $(\mathrm{mm} \mathrm{Hg}) ; \mathrm{RER}=$ respiratory exchange ratio; $\mathrm{Sp} \mathrm{O}_{2}=$ oxygen saturation as measured by pulse oximetry (\%); TV = tidal volume; $\mathrm{VAS}=$ visual analog scale; $\dot{V}_{E} \dot{V}_{\mathrm{CO}_{2}}=$ slope of the relationship between the $\dot{V}_{E}$ and $\dot{\mathrm{V}}_{\mathrm{CO}_{2}} ; \dot{\mathrm{V}}_{\mathrm{E}} \dot{\mathrm{V}}_{2}=$ slope of the relationship between the $\dot{\mathrm{V}}_{\mathrm{E}}$ and $\dot{\mathrm{V}}_{2} ; \mathrm{WR}=$ work rate $(\mathrm{W})$. Note: adapted and modified from Reference 36. 
factor. When performing a cardiopulmonary exercise test using a cycle ergometer, the Godfrey protocol (38) is very frequently used in children and adolescents. A strong advantage of cycle ergometry is the fact that the test will not be easily constrained by mechanical limitations of a patient (e.g., deviant walking patterns, soreness in ankle and knee joints) and a lower chance of movement artifacts in the electrocardiogram and blood pressure measurements.

For an adequate and complete interpretation of the acquired cardiopulmonary exercise test data, it is essential that the participant delivers a maximal effort. Although the integrated physiological response to exercise is measured objectively during cardiopulmonary exercise testing, performance during exercise testing strongly depends on the motivation of the participant. Consequently, motivating and encouraging the participant before and during the cardiopulmonary exercise test is very important, especially in children. As already mentioned, the leveling off of $\dot{\mathrm{V}}_{2}$, despite continuing exercise and increasing work rate, is considered the best evidence of a maximal effort. The absence of a clear plateau in $\dot{\mathrm{V}}_{2}$ at the end of an exercise test results in a dilemma. Has the participant performed an effort at, or near, the maximal level, despite the lack of a plateau in $\dot{\mathrm{V}}_{2}$ ? There are other objective physiological criteria available for this decision. For pediatric populations, it is recommended to use heart rate at $\dot{\mathrm{V}}_{2 \text { peak }}$ of at least $95 \%$ of
195 beats per min and the respiratory exchange ratio (carbon dioxide production divided by $\dot{\mathrm{V}}_{2}$ ) at $\dot{\mathrm{V}}_{\mathrm{O}_{2 \text { peak }}}$ of at least 1.00 as supplementary criteria for a maximal effort during cardiopulmonary exercise testing on a cycle ergometer (39). In addition, subjective criteria for a maximal effort (e.g., sweating, facial flushing, unsteady biking, and clear unwillingness to continue exercising despite strong encouragement) are valuable factors in drawing this conclusion.

Performance at a cardiopulmonary exercise test on a cycle ergometer is primarily measured by the attained $\dot{\mathrm{V}}_{2 \text { peak }}$ and the achieved peak work rate. When it is expected that a pediatric patient has a significantly reduced aerobic fitness, an exercise protocol in which the work rate increases more slowly is preferred. If the work rate increases too quickly, the maximal cardiopulmonary exercise test will be terminated prematurely, without maximally stressing the pulmonary, cardiovascular, and metabolic systems. The latter indicates that the child performed a submaximal effort, which severely restricts the interpretation of the cardiopulmonary exercise test. The ideal duration for a maximal cardiopulmonary exercise test is between 6 and 10 minutes for children (40), and between 8 and 12 minutes for adolescents and adults (41), and depends on the child's fitness. Experience has shown that children from 6 years of age can validly perform a cardiopulmonary exercise test in an exercise laboratory (42). There is still debate concerning the minimal age for performing a cardiopulmonary exercise test, as there are large interindividual differences. The main premise is that the child is able to understand instructions, as well as to cooperate according to these instructions. A necessity for measuring younger children is the availability of special equipment, such as a pediatric treadmill or cycle ergometer, especially for children below $125 \mathrm{~cm}$ in stature. In the Wilhelmina Children's Hospital of the University Medical Center Utrecht (Utrecht, the Netherlands), children as young as $4-5$ years of age have been tested successfully.

\section{Conclusions}

The cardiopulmonary exercise test is an important physiological investigation that can aid clinicians in their evaluation of exercise intolerance and dyspnea, as well as in their physiological reasoning and clinical decision-making. $\dot{\mathrm{V}}_{2 \max }$ is the gold standard measure of aerobic fitness, and is determined by the variables that define oxygen delivery in the Fick equation $\left(\dot{\mathrm{V}}_{2}=\right.$ cardiac output $X$ arteriovenous oxygen difference). Of the variables involved in oxygen delivery and utilization, the limitations of the cardiovascular system are the major factors responsible for limiting exercise in healthy children, as ventilation and gas exchange are sufficient to maintain arterial oxygen content up to peak exercise.

Author disclosures are available with the text of this article at www.atsjournals.org.

\section{References}

1 Ortega FB, Ruiz JR, Castillo MJ, Sjöström M. Physical fitness in childhood and adolescence: a powerful marker of health. Int $J$ Obes 2008;32:1-11.

2 Vanhees L, Lefevre J, Philippaerts R, Martens M, Huygens W, Troosters T, Beunen G. How to assess physical activity? How to assess physical fitness? Eur J Cardiovasc Prev Rehabil 2005;12:102-114.

3 Ruiz JR, Castro-Piñero J, Artero EG, Ortega FB, Sjöström M, Suni J, Castillo MJ. Predictive validity of health-related fitness in youth: a systematic review. Br J Sports Med 2009;43:909-923.

4 Blair SN, Kohl HW III, Paffenbarger RS Jr, Clark DG, Cooper KH, Gibbons LW. Physical fitness and all-cause mortality: a prospective study of healthy men and women. JAMA 1989;262:2395-2401.

5 Erikssen G, Liestøl K, Bjørnholt J, Thaulow E, Sandvik L, Erikssen J. Changes in physical fitness and changes in mortality. Lancet 1998; 352:759-762.

6 Myers J, Prakash M, Froelicher V, Do D, Partington S, Atwood JE. Exercise capacity and mortality among men referred for exercise testing. N Engl J Med 2002;346:793-801.

7 Lee SJ, Arslanian SA. Cardiorespiratory fitness and abdominal adiposity in youth. Eur J Clin Nutr 2007;61:561-565.

8 Hurtig-Wennlöf A, Ruiz JR, Harro M, Sjöström M. Cardiorespiratory fitness relates more strongly than physical activity to cardiovascular disease risk factors in healthy children and adolescents: the
European Youth Heart Study. Eur J Cardiovasc Prev Rehabil 2007; 14:575-581.

9 Nixon PA, Orenstein DM, Kelsey SF, Doershuk CF. The prognostic value of exercise testing in patients with cystic fibrosis. $N$ Engl J Med 1992;327:1785-1788.

10 Pianosi P, Leblanc J, Almudevar A. Peak oxygen uptake and mortality in children with cystic fibrosis. Thorax 2005;60:50-54.

11 Giardini A, Specchia S, Tacy TA, Coutsoumbas G, Gargiulo G, Donti A, Formigari R, Bonvicini M, Picchio FM. Usefulness of cardiopulmonary exercise to predict long-term prognosis in adults with repaired tetralogy of Fallot. Am J Cardiol 2007;99:1462-1467.

12 Giardini A, Hager A, Lammers AE, Derrick G, Müller J, Diller GP, Dimopoulos K, Odendaal D, Gargiulo G, Picchio FM, et al. Ventilatory efficiency and aerobic capacity predict event-free survival in adults with atrial repair for complete transposition of the great arteries. J Am Coll Cardiol 2009;53:1548-1555.

13 Shephard RJ, Allen C, Benade AJ, Davies CT, Di Prampero PE, Hedman R, Merriman JE, Myhre K, Simmons R. The maximum oxygen intake: an international reference standard of cardiorespiratory fitness. Bull World Health Organ 1968;38:757-764.

14 American Thoracic Society; American College of Chest Physicians. ATS/ACCP Statement on cardiopulmonary exercise testing. Am J Respir Crit Care Med 2003;167:211-277.

15 Bar-Or O, Rowland TW. Pediatric exercise medicine: from physiologic principles to health care application. Champaign, IL: Human Kinetics; 2004. 
16 Klijn PH, van der Net J, Kimpen JL, Helders PJ, van der Ent CK. Longitudinal determinants of peak aerobic performance in children with cystic fibrosis. Chest 2003;124:2215-2219.

17 Takken T, Terlingen HC, Helders PJ, Pruijs H, Van der Ent CK, Engelbert RH. Cardiopulmonary fitness and muscle strength in patients with osteogenesis imperfecta type I. J Pediatr 2004;145: 813-818.

18 van Brussel $\mathrm{M}$, Takken $\mathrm{T}$, van der Net $\mathrm{J}$, Engelbert $\mathrm{RH}$, Bierings $\mathrm{M}$, Schoenmakers MA, Helders PJ. Physical function and fitness in long-term survivors of childhood leukaemia. Pediatr Rehabil 2006;9: 267-274.

19 Verschuren O, Takken T, Ketelaar M, Gorter JW, Helders PJ. Reliability and validity of data for 2 newly developed shuttle run tests in children with cerebral palsy. Phys Ther 2006;86:1107-1117.

20 Takken T, van Bergen MW, Sakkers RJ, Helders PJ, Engelbert RH. Cardiopulmonary exercise capacity, muscle strength, and physical activity in children and adolescents with achondroplasia. $J$ Pediatr 2007;150:26-30.

21 Engelbert RH, Plantinga M, Van der Net J, Van Genderen FR, Van den Berg MH, Helders PJ, Takken T. Aerobic capacity in children with hemophilia. J Pediatr 2008;152:833-838, 838.e1.

22 van Brussel M, Takken T, Uiterwaal CS, Pruijs $\mathrm{HJ}$, van der Net $\mathrm{J}$, Helders PJ, Engelbert RH. Physical training in children with osteogenesis imperfecta. J Pediatr 2008;152:111-116, 116.e1.

23 Schoenmakers MA, de Groot JF, Gorter JW, Hillaert JL, Helders PJ, Takken T. Muscle strength, aerobic capacity and physical activity in independent ambulating children with lumbosacral spina bifida. Disabil Rehabil 2009;31:259-266.

24 Fick A. Über die Messung des Blutquantums in den Hertzventrikeln [in German]. Sitzungsber Phys Med Ges Würzburg 1870;2:16.

25 Myers J, Walsh D, Buchanan N, Froelicher VF. Can maximal cardiopulmonary capacity be recognized by a plateau in oxygen uptake? Chest 1989;96:1312-1316.

26 Rowland TW, Cunningham LN. Oxygen uptake plateau during maximal treadmill exercise in children. Chest 1992;101:485-489.

27 Armstrong $\mathrm{N}$, Welsman J, Winsley $\mathrm{R}$. Is peak $\mathrm{VO}_{2}$ a maximal index of children's aerobic fitness? Int J Sports Med 1996;17:356-359.

28 van Leeuwen PB, van der Net J, Helders PJM, Takken T. Inspanningsparameters bij gezonde Nederlandse kinderen. Geneeskunde en Sport 2004;37:126-132.
29 Tanaka H, Monahan KD, Seals DR. Age-predicted maximal heart rate revisited. J Am Coll Cardiol 2001;37:153-156.

30 Bongers BC, Hulzebos HJ, van Brussel M, Takken T. Pediatric norms for cardiopulmonary exercise testing: in relation to sex and age. 's Hertogenbosch: Uitgeverij BOXPress; 2014.

31 Borel B, Leclair E, Thevenet D, Beghin L, Gottrand F, Fabre C. Mechanical ventilatory constraints during incremental exercise in healthy and cystic fibrosis children. Pediatr Pulmonol 2014;49: 221-229.

32 Rowland T, Goff D, Martel L, Ferrone L. Influence of cardiac functional capacity on gender differences in maximal oxygen uptake in children. Chest 2000;117:629-635.

33 Obert P, Mandigouts S, Nottin S, Vinet A, N'Guyen LD, Lecoq AM. Cardiovascular responses to endurance training in children: effect of gender. Eur J Clin Invest 2003;33:199-208.

34 Turley KR, Wilmore $\mathrm{JH}$. Cardiovascular responses to treadmill and cycle ergometer exercise in children and adults. J Appl Physiol (1985) 1997;83:948-957.

35 Åstrand PO. Experimental studies of physical work capacity in relation to sex and age. Copenhagen: Munksgaard; 1952.

36 Bongers BC. Pediatric exercise testing: in health and disease. Maastricht: Universitaire Pers Maastricht; 2013.

37 Chang RK, Gurvitz M, Rodriguez S, Hong E, Klitzner TS. Current practice of exercise stress testing among pediatric cardiology and pulmonology centers in the United States. Pediatr Cardiol 2006;27:110-116.

38 Godfrey S. Methods of measuring the response to exercise in children. In: Godfrey S. Exercise testing in children: applications in health and disease. London: W.B. Saunders Company Ltd; 1974.

39 Armstrong N, Welsman JR. Aerobic fitness. In: Armstrong N, van Mechelen W. Paediatric exercise science and medicine. Oxford: Oxford University Press; 2008.

40 Hebestreit $\mathrm{H}$. Exercise testing in children-what works, what doesn't, and where to go? Paediatr Respir Rev 2004;5:S11-S14.

41 Buchfuhrer MJ, Hansen JE, Robinson TE, Sue DY, Wasserman K, Whipp BJ. Optimizing the exercise protocol for cardiopulmonary assessment. J Appl Physiol 1983;55:1558-1564.

42 LeMura LM, von Duvillard SP, Cohen SL, Root CJ, Chelland SA, Andreacci J, Hoover J, Weatherford J. Treadmill and cycle ergometry testing in 5- to 6-year-old children. Eur J Appl Physiol 2001;85: 472-478. 